\title{
Seismic Performance Analysis and Reinforcement Suggestion of RC Frame Structures
}

\author{
Linli Tan ${ }^{1}$, Ren Jiang ${ }^{1,}$, Qiuhong Zhao ${ }^{2}$ \\ ${ }^{1}$ School of Engineering and Management, Pingxiang University, Pingxiang, China \\ ${ }^{2}$ School of Architectural Engineering, Tianjin University, Tianjin, China \\ Email address: \\ 793499828@qq.com (Linli Tan), yyjrfzd@163.com (Ren Jiang), qzhao@tju.edu.cn (Qiuhong Zhao) \\ *Corresponding author
}

To cite this article:

Linli Tan, Ren Jiang, Qiuhong Zhao. Seismic Performance Analysis and Reinforcement Suggestion of RC Frame Structures. American Journal of Civil Engineering. Vol. 5, No. 6, 2017, pp. 371-378. doi: 10.11648/j.ajce.20170506.19

Received: October 28, 2017; Accepted: November 11, 2017; Published: December 6, 2017

\begin{abstract}
Nowadays, there have many reinforced concrete frame structures in China, which need to be reinforced in the event of strong earthquake. Therefore, quasi-static analysis method has adopted to investigate the seismic performance of the five story concrete frame structures and the different reinforcement schemes on the seismic performance of reinforced concrete (RC) structures. The results are shown that the numerical simulation of RC structures was verified by the Open Sees finite element method based on the existing experimental data. It was found that the weak layer of the RC frame structure mainly occurs in the plastic hinge region of the middle and lower floors of the RC frame structure. It was suggested that only the plastic hinge region of the middle and lower half of the RC frame structure and the bottom of the plastic hinge region of the bottom column of the RC frame structure could be reinforced, which will provides a theoretical basis for the RC frame reinforced method in the future.
\end{abstract}

Keywords: Reinforced Concrete, Quasistatic Analysis method, Failure Collapse Mode, Plastic Hinge, RC Frame Structure

\section{Introduction}

In recent years, suffered devastating earthquakes in domestic and international frequently, especially Wenchuan earthquake in 2008 China, a large number of RC (Reinforced Concrete) frame structure damage or even collapse after experiencing a number of strong earthquakes, mainly because the design of housing can't meet the requirements of the current seismic specifications before the Wenchuan earthquake, which in the role of strong earthquake occurred in varying degrees of damage or even collapse. With the improving continuously of people's awareness about the safety of buildings, but combined with the social and economic aspects of the actual situation to consider and can't have the integrity of the existing $\mathrm{RC}$ frame structure overturned reconstruction, so it is an inevitable choice for these engineering buildings to reinforce the strength and ductility of $\mathrm{RC}$ frame structural members to resist the ability to withstand stronger earthquakes.

Today's carbon fiber reinforced polymer (FRP) is widely $[1,2]$ used in the field of reinforcement engineering. It has been also proved in the actual project that FRP reinforcement is an effective way to improve the seismic resistance of buildings. There are a lot of researches on FRP reinforced $\mathrm{RC}$ frame structure in domestic and foreign scholars $[3,4,5$, 6 , 7], which show that the experimental and theoretical research is still in the early stage and the reinforcement of $\mathrm{RC}$ structure is not enough and more lacking, but the accuracy and rationality of the finite element numerical simulation modeling analysis are greatly improved. For the seismic performance can't meet the seismic requirements of the building structure, at the same time, taking into account the economic and social factors, the use of carbon fiber reinforcement method can make these $\mathrm{RC}$ frame structure to meet people's durability and safety requirements of the structure and continue to serve the community.

\section{Plastic Hinge Concept of Reinforced Concrete Frame Structure}

Based on that the beam-column element is mainly composed of Nonlinear Forced-Base Beam-Column Element 
and the Beam with Element in the finite element Open Sees plastic theory. The nonlinear deformation is mainly concentrated in the plastic hinge area $L_{P}$. When the model is used, the equations of the plastic zone length $L p$ of the RC frame structure proposed by Priestley and Pauly [8] is as follow:

$$
L_{p}=0.08 L+0.022 a_{s 1} d_{b} f_{y} \geq 0.044 f_{y} d_{b}
$$

In (1): $a_{s 1}$ represents the parameter steel slip. When the finite element analysis takes into account the slip of the steel $a_{s I}=1$, regardless of the slip of the steel $a_{s l}=0 ; f_{y}$ represents the yield strength of the steel; $d_{b}$ represents the diameter of the steel bar; and L represents the length of the RC frame structural member.

$\mathrm{RC}$ frame column plastic hinge length calculation $L p$ uses the calculation method proposed by Wang Fuming [9], and the equation is as follows:

$$
L_{p}=\left(0.12 h_{0}+0.04 a\right)\left(1.65-0.65 \frac{N}{f_{c} b h_{0}}\right)
$$

In (2), a represents the shear span ratio of the RC frame structure, $L_{p}$ is the length of the structural member, and $h_{0}$ is the effective cross section of the structure.

\section{Experimental Verification of RC Structure Based on Open Sees Finite Element}

\subsection{Test Model Verification of not Reinforced RC Frame Structure}

Based on the finite element Open Sees program, the quasi-static test of the whole two-dimensional plane reinforced concrete frame structure carried out by Professor Ye Liping of Tsinghua University in 2011 was carried out, and the researchers in all parts of the country were invited to carry out numerical simulation and simulation of the experimental model. The specific experimental data for the results of the trial study can be found in the website (http://www.collapseprevention.net/). The relevant experimental data has from the above website and the literature $[10,11,12]$. The experimental physical map is shown in Figure 1.

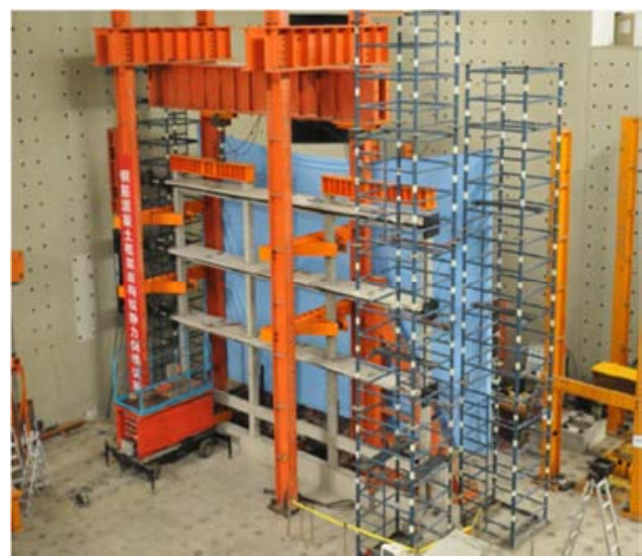

Figure 1. Testphysical map.

The RC frame structure simulation data and structural test data obtained by using Open Sees finite element numerical analysis are fitted together as shown in Figure 2. It is found that the finite element numerical simulation of $\mathrm{RC}$ frame structure model can simulate the hysteresis curve of the whole RC frame structure, which effectively validates the correctness of the finite element numerical analysis modeling model.

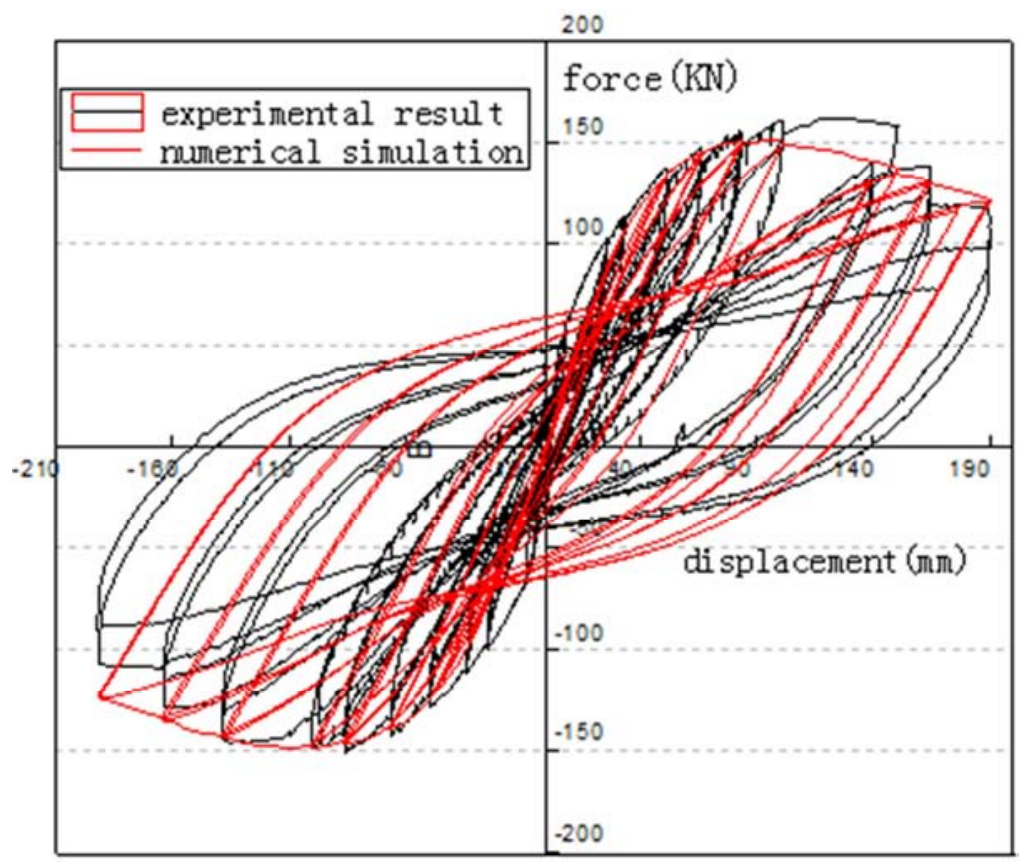

Figure 2. Comparison of simulation results and experimental results of RC frame structure. 


\subsection{Model Verification of FRP Reinforced RC Frame Structure Test}

Based on the quasi-static experiment of the RC frame structure of carbon fiber reinforced by the Professor Wang Xinling from Zhengzhou University in 2009, which are from the literature $[13,14]$ of the relevant experimental data and the experimental model is shown in Figure 3, reinforcement of $\mathrm{RC}$ frame structure analog data and structural test data obtained by using Open Sees finite element numerical analysis are fitted together for comparison as shown in Figure 4 , from which we can see that the finite element numerical simulation modeling of the established carbon fiber reinforced $\mathrm{RC}$ frame finite element model is an accurate simulation RC frame structure of the hysteresis curve, and the test data and simulation results are well match.

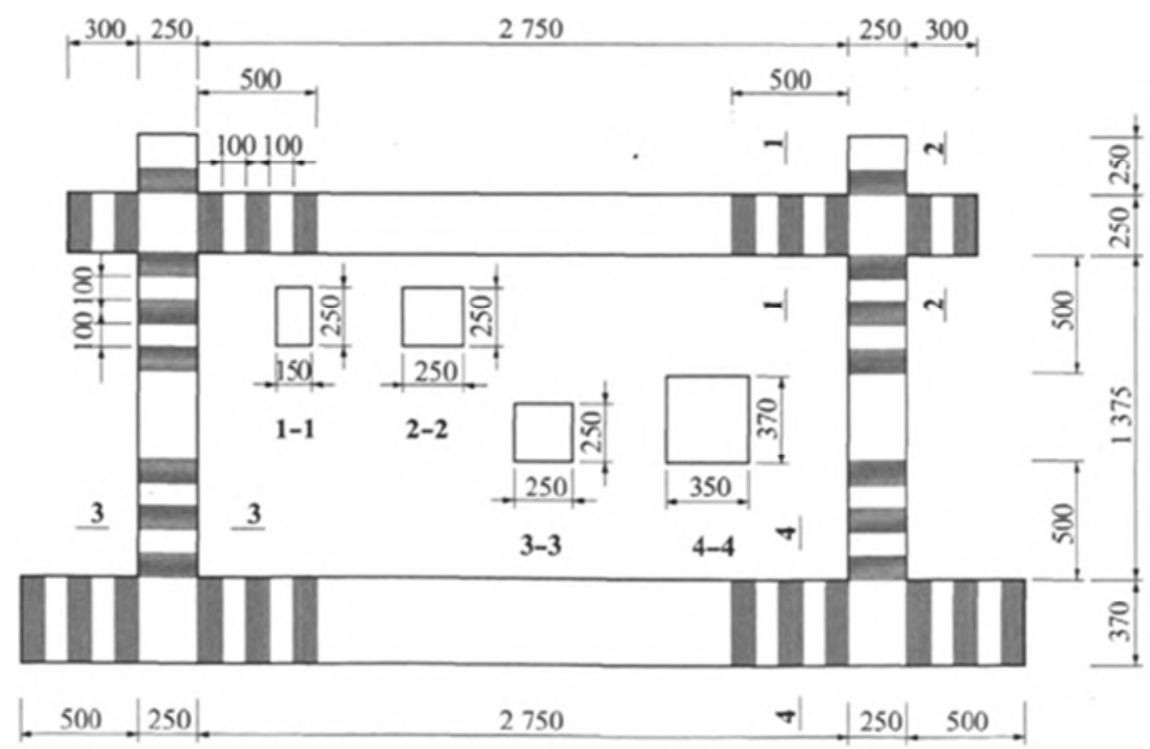

Figure 3. Test physical map.

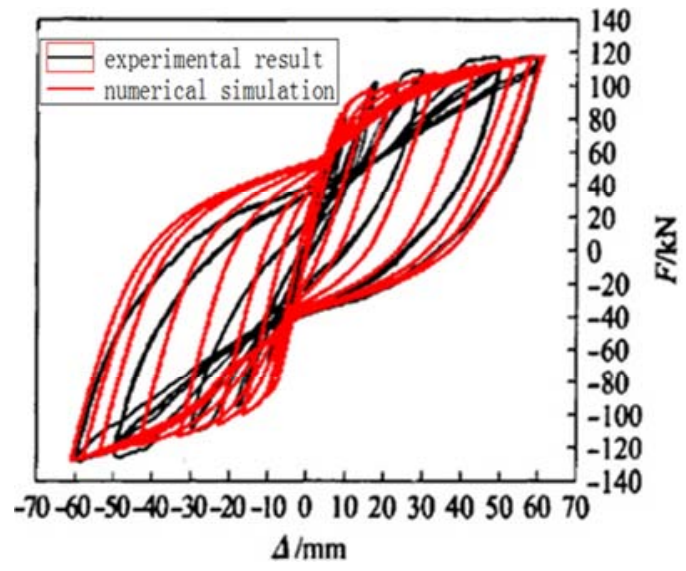

Figure 4. RC frame with carbon fiber reinforced simulation and test results comparison chart.

\section{Mechanical Properties Analysis of Test Materials}

\subsection{Mechanical Properties of Concrete}

The concrete test pieces were made of C30 commercial concrete building materials, and respectively, $150 \mathrm{~mm} \times 150 \mathrm{~mm}$ $\times 150 \mathrm{~mm}$ concrete cube test blocks are made of $6,150 \mathrm{~mm} \times$ $150 \mathrm{~mm} \times 300 \mathrm{~mm}$ concrete prisms are made of 6 . After 28 days in the same environment, according to the "concrete structure test method standard" (GB50152-92) specification requirements, the concrete cube block is loaded as shown in Figure 5. The damage to the test piece after loading is shown in Figure 6 . The compressive strength of the measured concrete cube is shown in Table 1. Concrete prism test concrete loading test device is shown in Figure 7. Through the three concrete prism test block measured concrete prism axial compressive strength loaded after the test, block damage is shown in Figure 8. The other three are used to measure the elastic modulus of the concrete block E and Poisson's ratio $r$. The compressive strength of the concrete prism was measured by the test loading as shown in Table 2. The elastic modulus $\mathrm{E}$ of the concrete is shown in Table 3. Poisson is shown in Table 4.

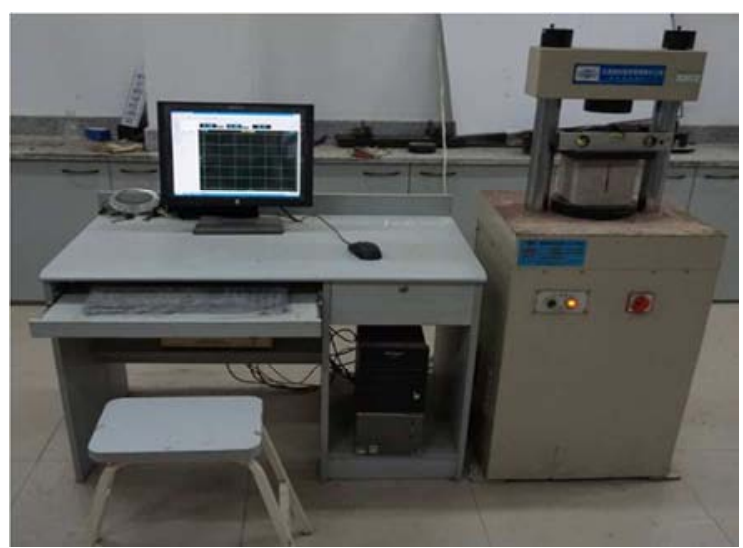

Figure 5. Physical block diagram of cube concrete before loading 


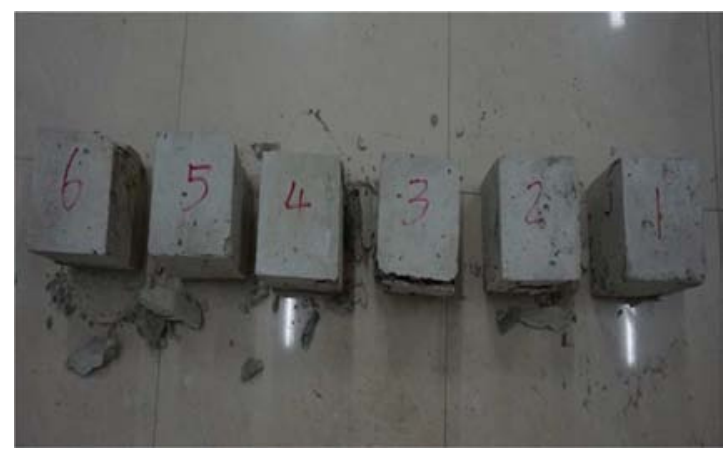

Figure 6. Physical block diagram of cube concrete after loading

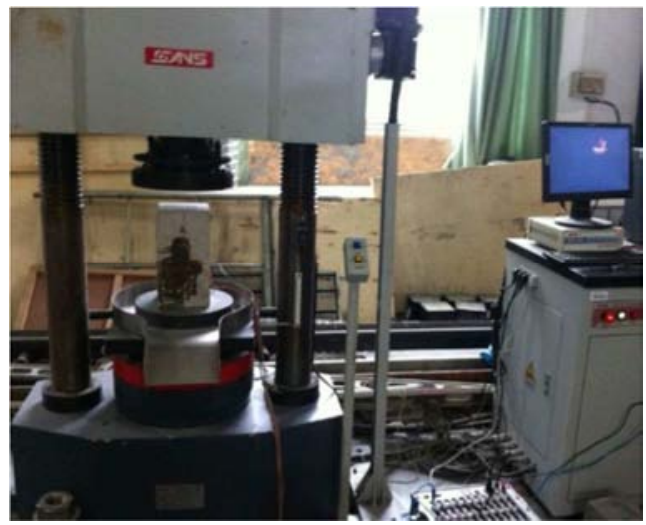

Figure 7. Concrete test device diagram.

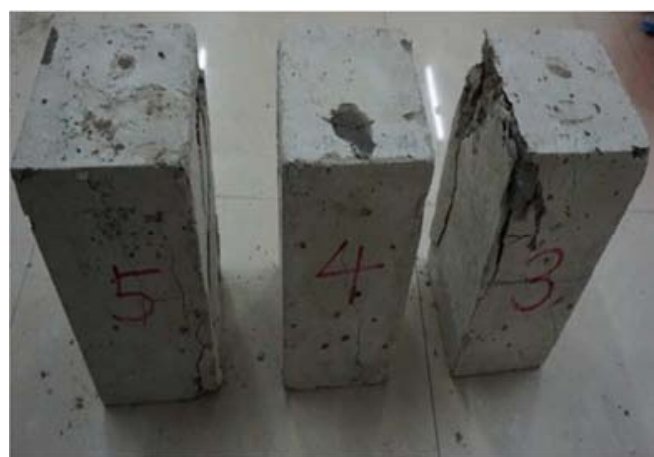

Figure 8. Physical diagram of axial compressive strength of prism after loading.

Table 1. Concrete cube compressive strength measured.

\begin{tabular}{llllllll}
\hline $\begin{array}{l}\text { Standard Test } \\
\text { Blocks for Concrete }\end{array}$ & $\mathbf{1}$ & $\mathbf{2}$ & $\mathbf{3}$ & $\mathbf{4}$ & $\mathbf{5}$ & $\mathbf{6}$ & $\begin{array}{l}\text { Average } \\
\text { Value }\end{array}$ \\
\hline $\begin{array}{l}\text { Measured Value } \\
f_{c u, k}(\mathrm{MPa})\end{array}$ & 28.8 & 28.1 & 29.8 & 27.2 & 28.3 & 28.6 & 28.47 \\
\hline
\end{tabular}

Table 2. Concrete prism compressive strength measured.

\begin{tabular}{lllll}
\hline Concrete prism test block & $\mathbf{3}$ & $\mathbf{4}$ & $\mathbf{5}$ & $\begin{array}{l}\text { Average } \\
\text { Value }\end{array}$ \\
\hline Concrete prism $f_{c k}(M P a)$ & 22.83 & 20.43 & 21.45 & 21.57 \\
\hline
\end{tabular}

Table 3. Concrete prism elastic modulus measured.

\begin{tabular}{lllll}
\hline Concrete prism test block & $\mathbf{1}$ & $\mathbf{2}$ & $\mathbf{6}$ & $\begin{array}{l}\text { Average } \\
\text { Value }\end{array}$ \\
\hline $\begin{array}{l}\text { Concrete prism } \\
\times 10^{4} \mathrm{~N} / \mathrm{mm}^{2}\end{array}$ & 3.41 & 3.02 & 3.73 & 3.39 \\
\hline
\end{tabular}

Table 4. Concrete prism poisson's ratio measured.

\begin{tabular}{lllll}
\hline Concrete prism test block & $\mathbf{1}$ & $\mathbf{2}$ & $\mathbf{6}$ & Average Value \\
\hline Poisson's ratio (r) & 0.24 & 0.21 & 0.26 & 0.24 \\
\hline
\end{tabular}

\subsection{Steel Performance}

In accordance with the "metal material at room temperature tensile test method" in the universal tensile testing machine on the tensile strength of the test load is shown in Figure 9. Specimen with a diameter of $6.5 \mathrm{~mm}$ round steel bars HPB300 is used as stirrups. Diameter of $10 \mathrm{~mm}$ hot rolled ribbed ribs HRB400E is as longitudinal reinforcement. Stirrups and Hot Rolled Ribbed Bars Glossary Calipers are shown in Figure 10. The diameter of the bars is shown in Table 5. The tensile damage of the steel is shown in Figure 11. The tensile properties of steel bars are shown in Table 6 .

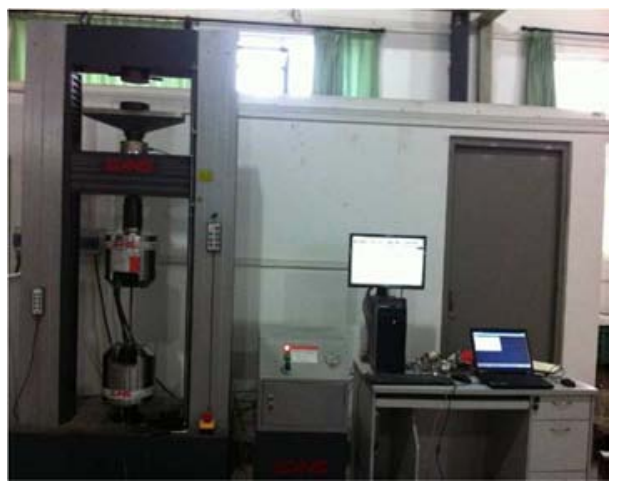

Figure 9. Steel tensile test device diagram.

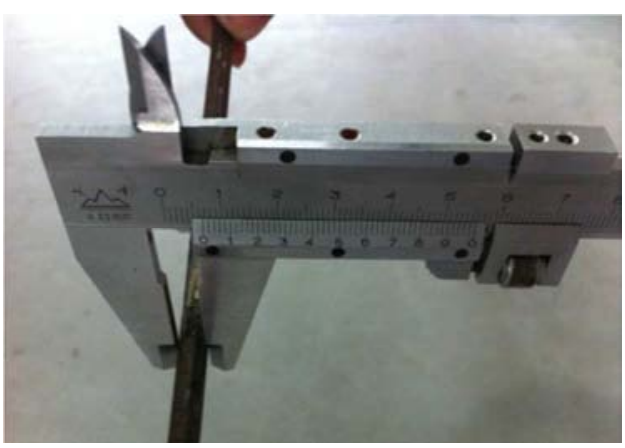

Figure 10. Steel bar vernier read the bar diameter chart.
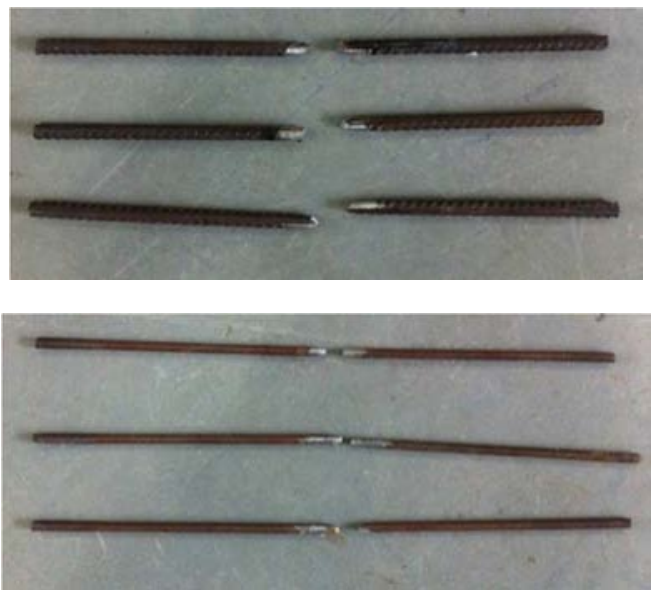

Figure 11. Physical map of steel bar after loading. 
Table 5. Bar diameter.

\begin{tabular}{llllll}
\hline \multirow{2}{*}{ Species } & \multirow{2}{*}{ Number / Diameter (mm) } & \multicolumn{3}{l}{ Measured position } & \multirow{2}{*}{ Average Value (mm) } \\
\cline { 3 - 5 } & & $\mathbf{1 / 3}$ position & $\mathbf{1 / 2}$ position & $\mathbf{2 / 3}$ position & \\
\hline \multirow{2}{*}{ HPB300 } & 1 & 6.58 & 6.52 & 6.60 & 6.56 \\
$\varnothing 6.5 \mathrm{~mm}$ & 2 & 6.56 & 6.54 & 6.62 & \\
& 3 & 6.58 & 6.52 & 6.50 & \multirow{2}{*}{10.08} \\
HRB400E & 1 & 10.04 & 10.16 & 10.02 & 10.18 \\
$\varnothing 10 \mathrm{~mm}$ & 2 & 10.06 & 10.12 & 10.08 & \\
\hline
\end{tabular}

Table 6. Tensile properties of steel bars.

\begin{tabular}{llll}
\hline Species & Yield Strength $(\boldsymbol{M P a})$ & Elastic Modulus $(\mathbf{G P a})$ & Ultimate strength $(\boldsymbol{M P a})$ \\
\hline HPB300 & 417.15 & 218 & 486.12 \\
HRB400E & 420.53 & 197 & 548.63 \\
\hline
\end{tabular}

\section{Structural Design and Structural Seismic Performance Analysis}

\subsection{Structural Design}

The design of the frame structure model follows the similarity theory $[15,16,17]$. According to the seismic design code, the seismic performance of the RC frame is analyzed by using the five-story three-span RC frame model as the research object. The height of the first layer of the reinforced concrete frame structure is $3.6 \mathrm{~m}$, the standard layer is $3.0 \mathrm{~m}$ and the span is $14.4 \mathrm{~m}$. The cross section of the frame column is $400 \mathrm{~mm} \times 400 \mathrm{~mm}$, the cross section of the frame beam is
$300 \mathrm{~mm} \times 400 \mathrm{~mm}$, and the thickness of the floor is $120 \mathrm{~mm}$. The frame layout is shown in Figure 12. The elevation of the frame structure is shown in Figure 13.

The design data includes: beam column concrete grade of $\mathrm{RC}$ frame structure with PKPM design is C30, longitudinal reinforcement is for the HRB400E grade steel. Stirrup is HPB300 grade steel. Basic wind pressure is $0.4 \mathrm{KN} / \mathrm{m}^{2}$. Surface roughness is $\mathrm{C}$ class. Do not consider snow load. The surface load of the standard layer is $3.32 \mathrm{KN} / \mathrm{m}^{2}$, and the live load of the standard floor is $2.0 \mathrm{KN} / \mathrm{m}^{2}$. People can't go up the roof. The live load is $3.3 \mathrm{KN} / \mathrm{m}^{2}$. Daughter wall is $1.2 \times 0.12$ square meters. The Design of ground motions group is Group 1. Design site categories is Class II. Site characteristics Period is $0.35 \mathrm{~s}$.

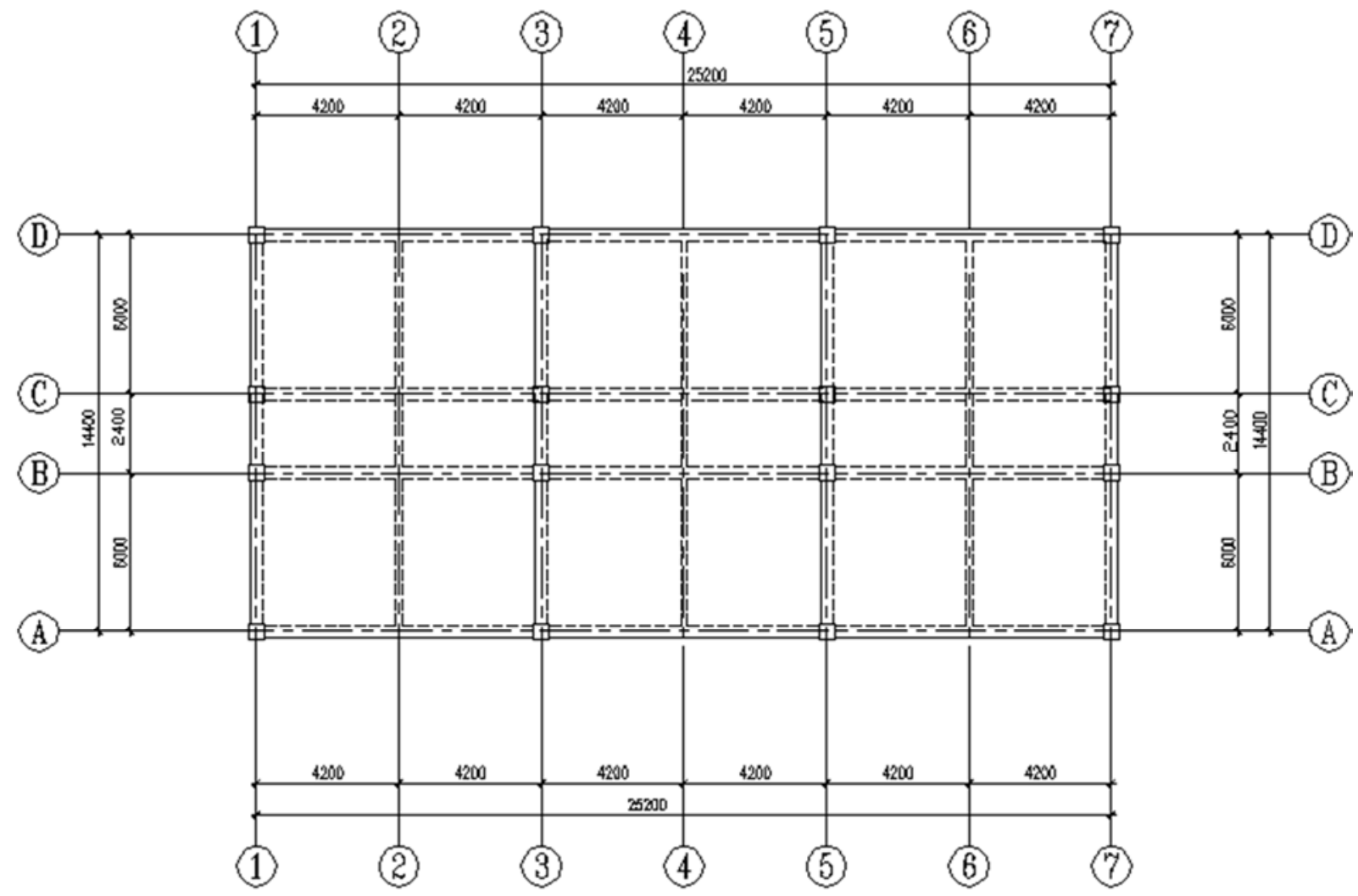

Figure 12. RC frame structure plan layout. 


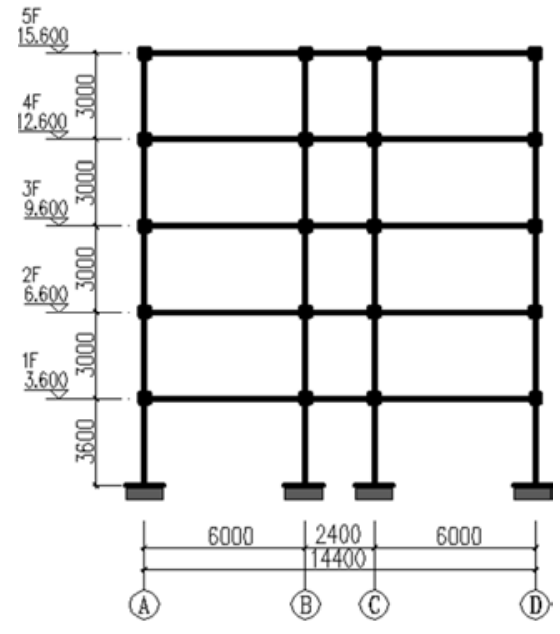

Figure 13. RC frame structure elevation layout.

\subsection{Seismic Performance Analysis of RC Frame Structure Without Reinforcement}

Based on the proven Open Sees finite element modeling, the concrete constitutive relation of concrete is Concrete 01, and the steel constitutive relationship is modeled by Steel 02 . The performance indexes of steel bars and concrete are shown in Table one to six. The results show that the seismic performance of the structures is investigated by using the inverted triangular distribution loading mode. According to the energy method, the RC method is given to determine the ultimate state of the $\mathrm{RC}$ frame structure, and the maximum interlayer displacement value of the $\mathrm{RC}$ frame structure is 0.02 according to the seismic structure of the engineering structure. Therefore, 0.02 is used as the maximum value of the $\mathrm{RC}$ frame structure. The elasto-plastic quasi-static analysis of the proposed unstiffened five-frame RC frame model is carried out, and the resulting inter-layer displacement angle is shown in Figure 14.

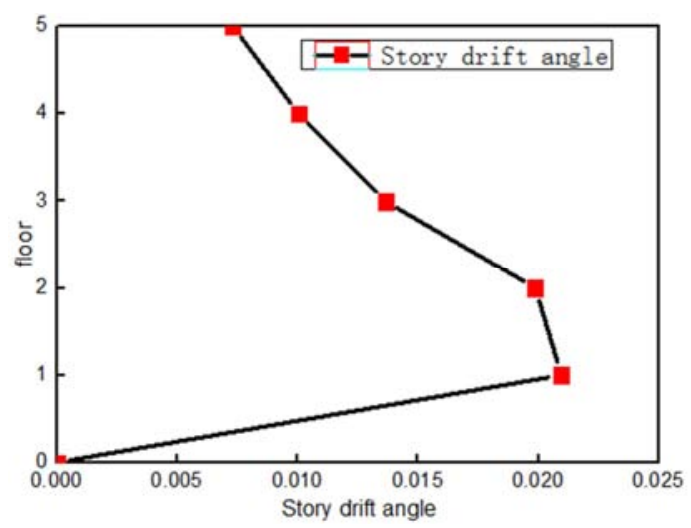

Figure 14. The displacement angle between layers.

It is shown that the structure failure occurs when the interlayer displacement angle of the RC frame structure at the bottom of the structure exceeds 0.02 . While the second layer of the RC frame structure has also reached the structural critical state of destruction. Therefore, the weak layer of RC frame structure mainly occurs in the middle and lower plastic hinge area of RC frame structure.

\section{Analysis and Suggestion on Reinforcement Schemes of FRP Reinforced RC Structures}

The results show that the interlayer displacement angle of the five - layer non - ductile RC frame structure appears in the lower part of the $\mathrm{RC}$ frame structure by analyzing the seismic performance of the RC five - story frame model without reinforcement. Based on the above model, the influence of different $\mathrm{RC}$ frame structure on the seismic performance of the structure is discussed. Therefore, following three kinds of programs of FRP reinforced RC frame structure plastic hinge area are proposed. In the first, the weak layer of the $\mathrm{RC}$ frame is mainly in the first layer. Therefore, only the plastic hinge area of the bottom structure of the frame structure and the beam-shaped plastic hinge area of the bottom floor are strengthened to examine the effect of the structural reinforcement scheme, as shown in Figure 15. In scheme 2, the weak layer of the RC frame structure after the reinforcement of the scheme 1 extends to the upper part of the frame, and the maximum point of the interlaminar displacement angle extends upwardly to the second layer of the frame structure. Therefore, the reinforcement of the frame structure and the lower three, and the effect of the structural reinforcement scheme has been shown in Figure 16. In the third aspect, for the program two reinforcement effect of a large degree of improvement, the damage degree of the RC frame structure will be developed to the whole $\mathrm{RC}$ frame structure. Therefore, the FRP reinforcement frame structure and the plastic pillar reinforcement program effect, as shown in Figure 17. But all reinforcement of the five-story frame is the use of FRP wrapped beam-shaped plastic hinge area, the reinforcement range is for the plastic hinge beam column end and bottom column plus. The RC column structure of the RC frame structure is $500 \mathrm{~mm}$, the reinforced plastic hinge zone is reinforced to $300 \mathrm{~mm}$, and the chamfer radius of the rectangular section is $20 \mathrm{~mm}$ by the length of the plastic hinge.

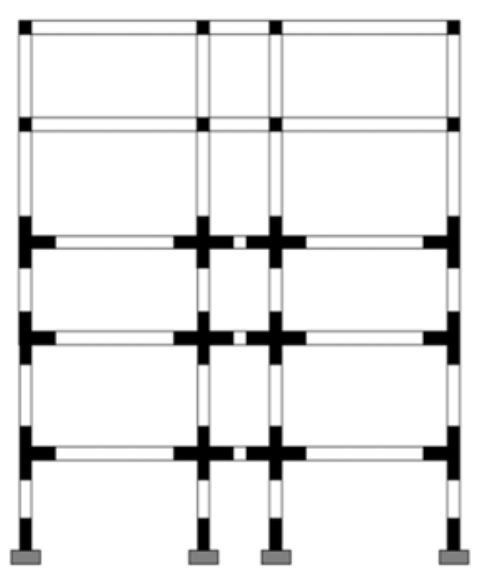

Figure 15. Reinforcement Scheme I. 


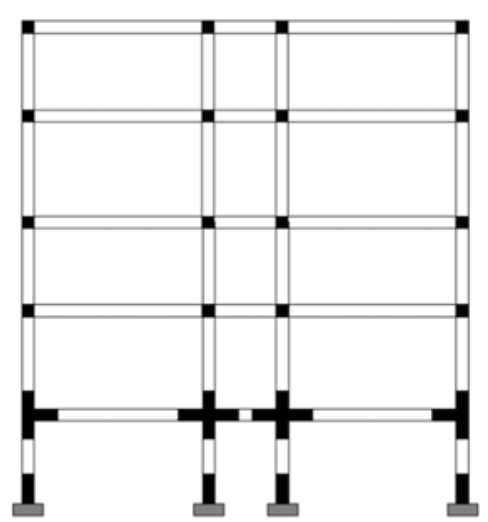

Figure 16. Reinforcement Scheme II.

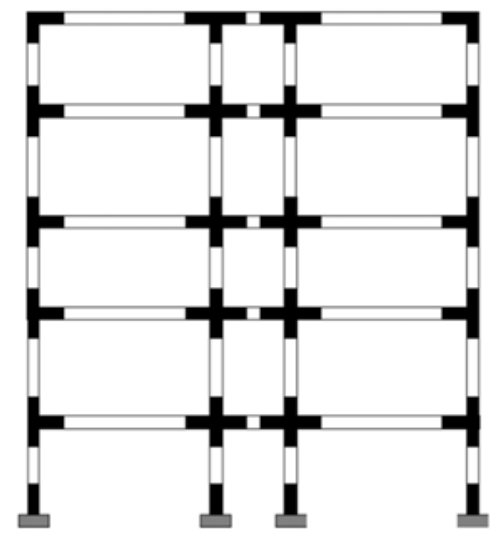

Figure 17. Reinforcement Scheme III.

According to the comparison of three different reinforcement schemes, the interlaminar displacement angles corresponding to the weak layers of the $\mathrm{RC}$ frame structure are compared and analyzed by the quasi-static analysis method, as shown in Figure 18.

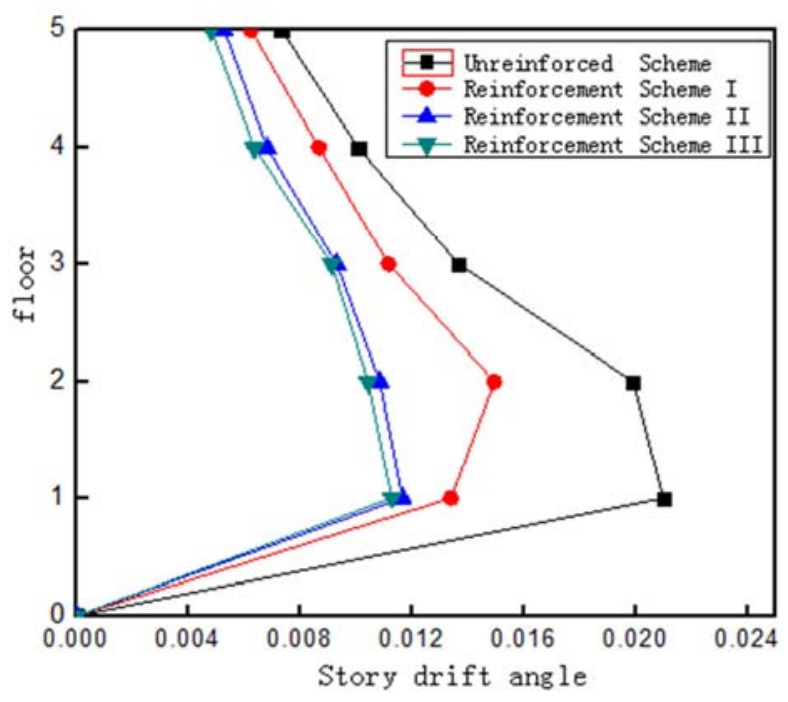

Figure 18. Comparison of the displacement angles of $R C$ frames.

The results show that the $\mathrm{RC}$ frame structure of the three schemes is $37.2 \%, 48.8 \%$ and $52.6 \%$ lower than that of the unreinforced RC frame structure when the interlayer displacement angle is 0.02 . In view of the existence of a large number of low-level non-ductile RC frame structures in China, the limit value of the inter-layer displacement angle of $\mathrm{RC}$ frame structure is in the second layer after reinforcement of scheme FRP. Before reinforcement, RC frame the structure of the interlayer displacement angle limit occurred in the bottom. It can be seen that after the FRP reinforcement is used, the damage from the displacement angle is transferred from the bottom to the second layer of the structure. Reinforcement effect is not obvious, but it has been in the structure of the damage within the scope of security. After the FRP reinforcement, the maximum displacement angle of the $\mathrm{RC}$ frame structure is significantly lower than that of the unreinforced RC frame structure, and after the FRP is reinforced, the structure is in the safe range of destruction. Therefore, the above research shows that reinforcement of RC frame structure with FRP can effectively improve the seismic capacity of reinforced structure. However, the overall seismic performance of the $\mathrm{RC}$ frame structure is greatly improved by strengthening the plastic hinge area of the RC frame and the bottom column in the middle and lower half of the RC frame. The seismic performance of the RC frame structure is improved greatly, and the results of the two reinforcement schemes are similar. Considering the economic and social factors, it is suggested that only the bottom of the RC frame structure should be reinforced and the bottom of the bottom pillar plastic hinge area of the bottom pillar, that is, Option 2 is the optimal reinforcement scheme.7. Conclusion

According to code for seismic design in china that does not consider the seismic design, in this paper, through the quasi static study of the five - story RC frame structure represented by the middle and low layers, the effects of the overall seismic behavior of the $\mathrm{RC}$ frame structure and the different reinforcement schemes on the aseismic behavior of the RC structures are studied. The main conclusions are as follows:

(1) Based on the experimental data, the finite element numerical analysis of $\mathrm{RC}$ frame structure without reinforcement and FRP reinforcement is carried out by using Open Sees, which verifies the correctness of Open Sees finite element modeling.

(2) The seismic performance of the RC frame structure is studied by quasi - static analysis method. The results show that the weak layer of $\mathrm{RC}$ frame structure mainly occurs in the middle and lower plastic hinge area of RC frame structure.

(3) The effects of different reinforcement schemes on the seismic performance of RC frame structures represented by five RC frame structures are studied and it is shown that it is only necessary to strengthen the bottom of the $\mathrm{RC}$ frame structure and the bottom of the bottom pillar plastic hinge area, which provides the theoretical basis for the reinforcement of the RC frame structure in the future.

\section{Acknowledgements}

The authors gratefully acknowledge the Natural science Foundation of China, and American Journal of Civil Engineering (ISSN Print: 2330-8729ISSN Online: 2330-8737) 


\section{References}

[1] CECS 164: 2003-2007 Technical Specification for Strengthening Concrete Structures with Carbon Fiber Reinforced Polymer Laminate [S].

[2] AL-SALlOUM Y A, ALMUSALlaM T H. Seismic response of interior RC beam-column joints upgraded with FRP sheets I-Experimental study [J]. Journal of Composites for Construction, 2007. 11(6): 575-589.

[3] Weiguo Wang, Zhongfan Chen, Wenrang Chen. Seismic Performance Analysis of FRP Reinforced Frame [J]. Engineering Seismic and Reinforcement, 2009, 31(1): 91-96.

[4] Liping Jiang, Shougao Tang, Wei Song, Zheng Cao. Dynamic Response Analysis of RP-covered Concrete Frame Structure [J]. Engineering mechanics, 2004, 21(2): 194-198.

[5] Galal K, and El-Sokkary H. Analytical evaluation of seismic performance of RC frames rehabilitated using FRP for increased ductility of members [J]. Journal of Performance of Constructed Facilities, 2008, 22(5): 276-288.

[6] El-Sokkary H. and Galal K. Analytical investigation of the seismic performance of $\mathrm{RC}$ frames rehabilitated using different rehabilitation techniques [J]. Engineering Structures, 2009, 31(9): 1955-1966.

[7] Zhicong Wang. Seismic Analysis and Conceptual Design of FRP Reinforced Non-ductile Reinforced Concrete Frame [D]. Harbin: Harbin Institute of Technology, 2012.

[8] Priestley M J N, Seible F, Calvi G M S. Seismic Design and Retrofit of Bridges [M]. New York: John Wiley \& Sons; 1996.
[9] Fuming Wang, Jianmin Zeng, Lian Duan. Experimental Study on Plastic Hinge of Reinforced Concrete Columns [J]. Journal of Taiyuan University of Technology, 1989, 20(4): 20-29.

[10] Xinzheng Lu, Lieping Ye, Peng Pan and so on. Experimental Study and Quasi-static Collapse Test of Reinforced Concrete Frame Structure I: Frame test [J]. Building Structure, 2012, 42(11): 20-26.

[11] Xinzheng Lu, Lieping Ye, Peng Pan and so on. Experimental Study and Quasi-static Collapse Test of Reinforced Concrete Frame Structure II: Key component test [J]. Building Structure, 2012, 42(11): 23-26.

[12] Xinzheng Lu, Lieping Ye, Peng Pan and so on. Experimental Study and Quasi-static Collapse Test of Reinforced Concrete Frame Structure III: Simulation results analysis [J]. Building Structure, 2012, 42(11): 27-30.

[13] Xinling Wang, Juntao Zhu, Lin Lv, Zhangtang Yao and so on. Experimental Study on Seismic Behavior of Carbon Fiber Reinforced Concrete Rrame Structure [J]. Journal of Zhengzhou University, 2008, 29(4): 81-85.

[14] Qizhen Zheng, Dong Wang, Yu Tang, Wei Kang. Experimental Study on Seismic Behavior of Carbon Fiber Unreinforced Concrete Rrame Structure [J]. Journal of Building Materials, 2011, 14(5): 591-596.

[15] Junjie Yang. Similarity Theory and Structural Model Test [M]. Wuhan: Wuhan University of Technology Press, 2006.

[16] Water Resources and Hydropower Research Institute, Nanjing Water Conservancy Research Institute. Hydraulic model test [M]. Beijing: Water Resources and Electricity Press, 1985.

[17] Dongqi Zuo and so on. The Theory and Method of Model Test [M]. Beijing: Water Resources and Electricity Press, 1984. 